\title{
Integration of CD45-positive leukocytes into newly forming lymphatics of adult mice
}

\author{
K. Buttler ${ }^{1}$ M. Lohrberg ${ }^{1}$ G. Gross ${ }^{2}$ H. A. Weich ${ }^{3}$ J. Wilting ${ }^{1}$
}

Accepted: 21 December 2015 / Published online: 9 January 2016

(C) The Author(s) 2016. This article is published with open access at Springerlink.com

\begin{abstract}
The embryonic origin of lymphatic endothelial cells (LECs) has been a matter of controversy since more than a century. However, recent studies in mice have supported the concept that embryonic lymphangiogenesis is a complex process consisting of growth of lymphatics from specific venous segments as well as the integration of lymphangioblasts into the lymphatic networks. Similarly, the mechanisms of adult lymphangiogenesis are poorly understood and have rarely been studied. We have recently shown that endothelial progenitor cells isolated from the lung of adult mice have the capacity to form both blood vessels and lymphatics when grafted with Matrigel plugs into the skin of syngeneic mice. Here, we followed up on these experiments and studied the behavior of host leukocytes during lymphangiogenesis in the Matrigel plugs. We observed a striking co-localization of $\mathrm{CD} 45^{+}$leukocytes with the developing lymphatics. Numerous $\mathrm{CD} 45^{+}$cells expressed the LEC marker podoplanin and were obviously integrated into the lining of lymphatic capillaries. This indicates that, similar to inflammation-induced lymphangiogenesis in man, circulating $\mathrm{CD} 45^{+}$cells of adult mice are capable of initiating lymphangiogenesis and of adopting a
\end{abstract}

Electronic supplementary material The online version of this article (doi:10.1007/s00418-015-1399-y) contains supplementary material, which is available to authorized users.

J. Wilting

joerg.wilting@med.uni-goettingen.de

1 Department of Anatomy and Cell Biology, University Medical School Göttingen, Göttingen, Germany

2 Department of Gene Regulation, Helmholtz Centre for Infection Research, Brunswick, Germany

3 Department of Chemical Biology, Helmholtz Centre for Infection Research, Brunswick, Germany lymphvasculogenic cellular differentiation program. The data are discussed in the context of embryonic and inflammation-induced lymphangiogenesis.

Keywords Lymphatic endothelial cell . Lymphangioblast · Lymphangiogenesis · Lymphvasculogenesis · Endothelial progenitor cell . Mesenchymal stem cell

\section{Introduction}

The embryonic origin of the lymphatic vascular system has been studied for more than a hundred years, but controversies still exist. Florence Sabin was among the first to study embryonic lymphangiogenesis, and stated that, in pigs, lymphatic vessel formation takes place via sprouting from specific segments of deep embryonic veins (Sabin 1909). In contrast, Kampmeier postulated an additional mesenchymal origin of lymphatics (Kampmeier 1912). Our insight into the mechanisms regulating lymphatic vessel formation has greatly increased by the imaging of labeled cell lines in living animals, predominantly supporting Kampmeier's hypothesis. For instance, in zebrafish embryos, precursor cells were found to migrate from the cardinal vein to the horizontal myoseptum to generate parachordal lymphangioblasts in this area (Küchler et al. 2006; Yaniv et al. 2006; Hogan et al. 2009; Isogai et al. 2009). These parachordal lymphangioblasts could be pursued to migrate along arteries and to remodel into major trunk lymphatic vessels thus forming the thoracic duct (Yaniv et al. 2006; Bussmann et al. 2010; Cha et al. 2012). The data provided evidence for an intermediate mesenchymal phase of lymphangiogenesis in fish. Although a strong conservation of genes controlling lymphangiogenesis could be detected between zebrafish 
and mammals (Schulte-Merker et al. 2011; Koltowska et al. 2013), in higher vertebrates the lymphatic vascular system is more complex than in fish, which hardly possess any epifascial, dermal lymphatics. Moreover, organ-specific lymphatic vascular patterns can be seen in higher vertebrates, but the cellular origins of embryonic lymphatics in diverse compartments of the body are still subject of controversial discussions.

Apart from the embryo, lymphangiogenesis takes place under pathological conditions (Wilting et al. 2009; Tammela and Alitalo 2010). In murine experimental models employing the lung and the skin, it could be shown that acute inflammation is able to induce lymphangiogenesis effectively (Pullinger and Florey 1937; Baluk et al. 2005). Thereby, pro-inflammatory factors such as interleukin- 1 and tumor necrosis factor- $\alpha$ induce the upregulation of the lymphangiogenic vascular endothelial growth factor-C (VEGF-C; Cha et al. 2007). But also in man, acute inflammation is a strong pro-lymphangiogenic stimulus (Kerjaschki et al. 2006), whereas chronic inflammation obviously has a deleterious effect on the lymphatics. After repeated inflammation collectors seem to loose their contractility, lymph then coagulates and the vessels subsequently obliterate (Földi and Földi 2003). During inflammation-induced kidney transplant rejection in man, massive lymphangiogenesis into the parenchyma of the rejected kidneys has been observed; additionally, there was evidence for the integration of circulating cells into the lining of the newly developing lymphatics (Kerjaschki et al. 2006). However, it is still a matter of debate, if the mechanisms of lymphangiogenesis in the mouse recapitulate those in man.

We have recently shown that endothelial progenitor cells (EPCs) isolated from the lungs of adult mice have the capacity to form both blood vessels and lymphatics, when grafted into the skin of mice using Matrigel ${ }^{\circledR}$ plugs. Thereby, hem- and lymphangiogenesis were initiated via stimulation of the EPCs either by direct application of growth factors such as VEGF-A and basic fibroblast growth factor (FGF; Schniedermann et al. 2010), or by co-injection of mesenchymal stem cells (MSCs), which secrete a variety of angiogenic factors. Thereby, we observed no participation of MSCs in the formation of the vascular wall (Buttler et al. 2014). Here, we followed up on these experiments and studied the behavior of host leukocytes during lymphangiogenesis in the Matrigel ${ }^{\circledR}$ plugs. We found a significant co-localization of $\mathrm{CD} 45^{+}$leukocytes with the developing lymphatics, and a considerable number of these cells were obviously integrated into the lining of newly formed lymphatics. This led us to the conclusion that, similar to the mechanisms of inflammation-induced lymphangiogenesis in man, circulating $\mathrm{CD} 45^{+}$cells of adult mice are capable of initiating a lymphvasculogenic program.

\section{Materials and methods}

\section{Animals}

Lung-derived EPCs and bone marrow-derived mesenchymal stem cells (MSCs) were isolated from C57/B1.6 mice, and the cells were grafted into adult C57/B1.6 mice. For the transplantation experiments, we used 8-12 weeks-old female mice. All experiments were approved by our local institutional animal care committee and the Lower Saxony state council on animal care (LAVES). The experiments corresponded to the requirements of the American Physiological Society.

\section{Isolation and culture of EPCs and MSCs}

All cells were isolated from C57/B1.6 mice. EPCs were isolated from mouse lungs using a magnetic cell separation method that has already been described by Schniedermann et al. (2010). Briefly, the lungs of adult mice were dissected after perfusion, minced and digested using collagenase A. A single cell suspension of the collected cells was produced with a $40 \mu \mathrm{m}$ cell strainer, and $\mathrm{CD} 31^{+}$cells were cultivated after magnetic activated cell sorting using antiCD31-coated Dynabeads ${ }^{\circledR}$ (Thermo Fischer Scientific). After 8-10 days, cells were separated again using FACS sorting with anti-CD31 antibodies.

MSCs were isolated from bone marrow as described by Soleimani and Nadri (2009). Shortly, mice were killed by cervical dislocation and the hind limbs were separated from the trunk after removal of the skin. Muscles and connective tissue was then removed from the tibia and the femur under sterile conditions. To harvest bone marrow, the distal ends of tibia and femur were cut off and bone marrow was flushed out with PBS by insertion of a needle into the cancellous bone. The cell suspension was then filtered, and bone marrow cells were transferred into culture dishes. The cells were used between passages 6-10 (MSCs) and 8-24 (EPCs). As in our previous studies (Schniedermann et al. 2010; Hoffmann et al. 2006), MSCs and EPCs were cultured in DMEM enriched with FCS in 24- and 6-well plates $\left(\mathrm{Nunc}^{\circledR}\right)$. EPCs were cultured in gelatine-coated wells or cell culture flasks.

\section{Assessment of vessel formation in vivo}

For the in vivo experiments, MSCs and EPCs were trypsinized and counted. For the experiments with each single cell type, $1 \times 10^{6}$ cells were used. When the two cell types were combined in a $1: 1$ mixture, $0.5-1 \times 10^{6}$ cells were used for each cell type. Cells were centrifuged and the pellets were dissolved in $300 \mu \mathrm{l}$ of cold Matrigel ${ }^{\circledR}$ (Corning, 
Wiesbaden, Germany). The mice were shaved and mildly sedated by intraperitoneal injection of ketamine $(100 \mathrm{mg} /$ $\mathrm{kg}$ body weight). Matrigel plugs with or without cells were injected subcutaneously into the left and right dorsal lumbar region (two injections per animal). After 7-9 days, the animals were killed, the skin was dissected, the Matrigel plugs photographed in situ, excised and fixed with $4 \%$ paraformaldehyde (PFA). The specimens were rinsed in PBS, immersed with saccharose and embedded in tissue freeze medium (Neg-50, Richard-Allan Scientific, Mi). The numbers of experiments were: Matrigel without cells $(n=11)$, Matrigel with EPCs (5), Matrigel with MSCs (6), Matrigel with EPCs and MSCs (26).

\section{Histology and immunohistology}

Frozen specimens were sectioned at $16 \mu \mathrm{m}$, mounted on slides, and stained with hematoxylin and eosin (HE). For the immunofluorescence studies, non-specific binding was blocked by the incubation with $2 \%$ bovine serum albumin (BSA) for $1 \mathrm{~h}$ prior to the incubation with the primary antibodies. Primary antibodies were anti-mouse CD31 (rat clone MEC13.3; 1:50, BD), anti-podoplanin (syrian hamster clone 8.1.1, 1:1000, Hybridoma Bank, Iowa), anti-Prox1 (rabbit polyclonal, 1:500, Reliatech, Germany), and antimouse CD45 (rat monoclonal, 1:50, BD). After incubation with the primary antibodies for $1 \mathrm{~h}$, sections were rinsed and the secondary antibodies were applied: goat anti-rat Alexa594/or Alexa488, donkey anti-rabbit Alexa488, goat anti-hamster Alexa594/or Alexa488 (all from Invitrogen). Dapi was used to counter-stain all nuclei. The sections were mounted under coverslips using Fluoromount-G (Southern Biotechnology, US) and studied with Axio Imager Z1 with ApoTome device (Zeiss, Göttingen, Germany).

\section{Results}

In all experiments performed with Matrigel ${ }^{\circledR}$ plugs containing a 1:1 mixture of EPCs and MSCs, the stereomicroscopic inspection revealed the presence of blood vessels in the plugs already after 7-9 days. These vessels were obviously highly fragile since careful dissection of the skin always resulted in hemorrhage in the plug region. Matrigel ${ }^{\circledR}$ controls and plugs containing only each single cell type were macroscopically and microscopically free of vessels, as it was shown in detail recently (Buttler et al. 2014). The development of vessels in the EPC/MSC-containing plugs was verified by immunofluorescence using antibodies against CD31/PECAM1. In normal tissues, blood vascular endothelial cells (BECs) are strongly CD31/PECAM1-positive, whereas lymphatic endothelial cells (LECs) are just weakly positive and characterized by their nuclear expression of the Prox 1 transcription factor (Wilting et al. 2002). Both types of expression pattern could be found in EPC/MSC-containing Matrigel ${ }^{\circledR}$ plugs, clearly documenting the development of blood vessels and lymphatic networks (Fig. 1). The newly formed vessels were made up of a mosaic containing grafted EPCs and host endothelial cells. We did not find any signs for the integration of MSC into these vessels (Buttler et al. 2014). Studies using antibodies against the pan-leukocyte marker CD45 revealed massive infiltration of leukocytes into the experimental plugs, indicating an inflammatory-type of lymphangiogenesis, although a syngeneic model was used in our grafting experiment. We observed a significant co-localization of host leukocytes with the podoplanin-positive lymphatic capillary networks in the plugs (Fig. 2), indicating an active participation of the leukocytes in adult lymphangiogenesis. Interestingly, a subpopulation of $\mathrm{CD} 45^{+}$cells assumed endothelial-like morphology and was obviously integrated into the newly forming lymphatic networks (Fig. 3). In many cases, like those shown in Figs. 2 and 3, the new lymphatics formed delicate capillary-like networks, but we also observed sinusoid-like lymphatics. Again, round $\mathrm{CD} 45^{+}$leukocytes could clearly be distinguished from endothelial-like cells, which co-expressed CD45 and podoplanin (Fig. 4). In rare case we found lymphatics with a wide lumen. In such cases we observed cells that obviously lined the lumen of the vessel (Fig. 5; Suppl. Movie 1). Our data provide strong evidence for the existence of leukocytes with lymphvasculogenic potential in adult mice.

\section{Discussion}

\section{Lymphangiogenic potential of endothelial progenitor cells}

We have previously shown that the lung of mice contains EPCs that possess the potential to differentiate into both BECs and LECs (Schniedermann et al. 2010; Buttler et al. 2014). Thereby, the EPCs exert their hem- and lymphangiogenic program only after exogenous stimulation, either by direct application with VEGF-A and FGF, or after cotransplantation with MSCs (Melero-Martin et al. 2008; Schniedermann et al. 2010; Lin et al. 2012; Buttler et al. 2014). It has to be pointed out that rodents have the capacity to regenerate lung tissue after resection, which has not been observed in the human. Regeneration of mouse lung is accompanied by the formation of new blood vessels (Konerding et al. 2012); however, the development of lymphatics has not been studied in this model. In our experiments, the lymphatics in the Matrigel plugs are formed by a mosaic of grafted EPCs and host-derived LECs, which was shown by the use of GFP-labeled EPCs (Buttler et al. 2014). Since we used a syngeneic mouse model, it is admissible to 


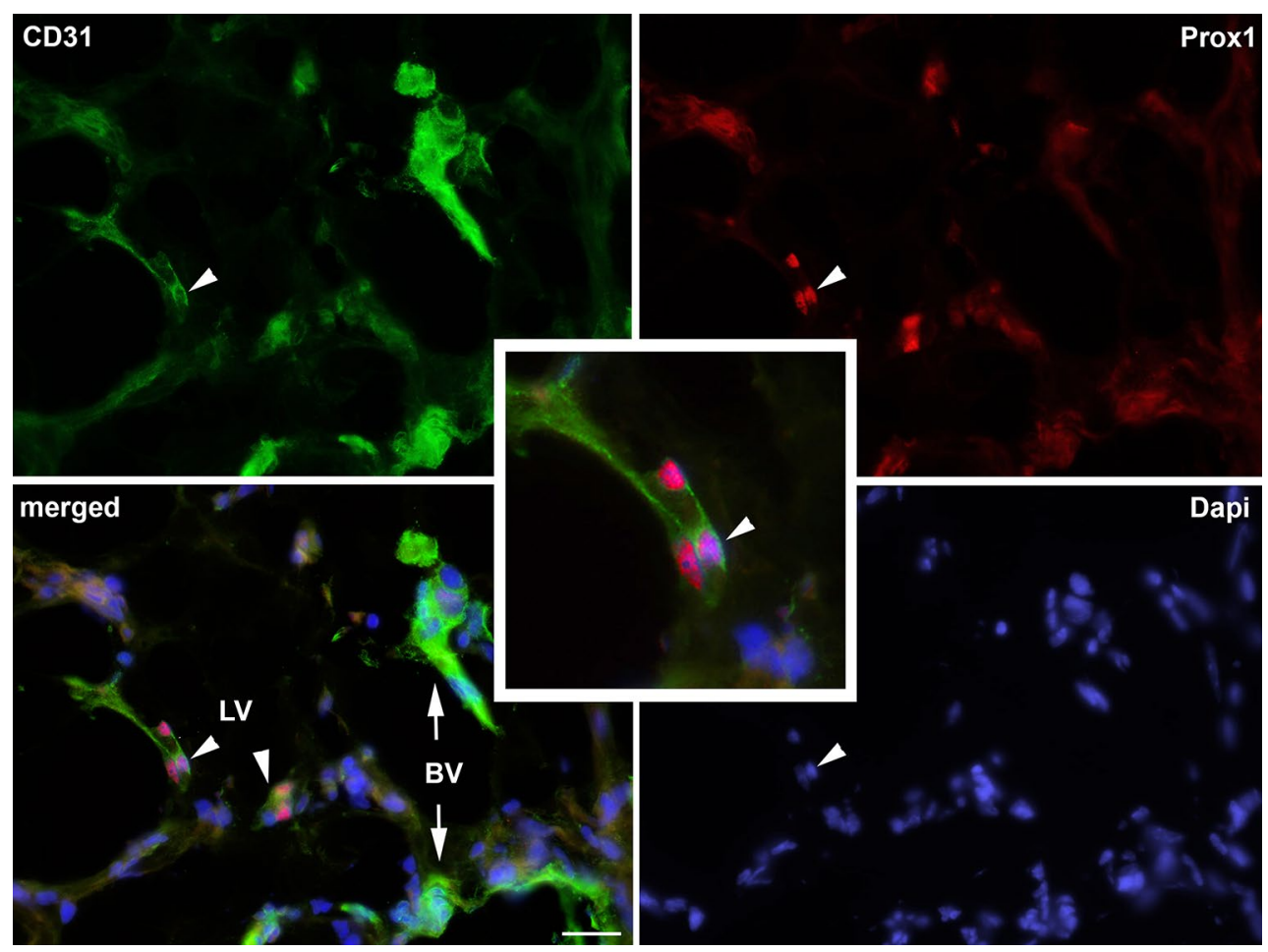

Fig. 1 Verification of lymphatics in the Matrigel plugs with CD31 (green) and Proxl (red) antibodies. The pan-endothelial marker $C D 31$ stains blood vessels $(B V)$ strongly and lymphatics $(L V)$ weakly.
Proxl marks the nuclei of LECs (arrowheads) as shown at higher magnification in the inset. Nuclei are counter-stained with Dapi (blue). Bar $30 \mu \mathrm{m}$
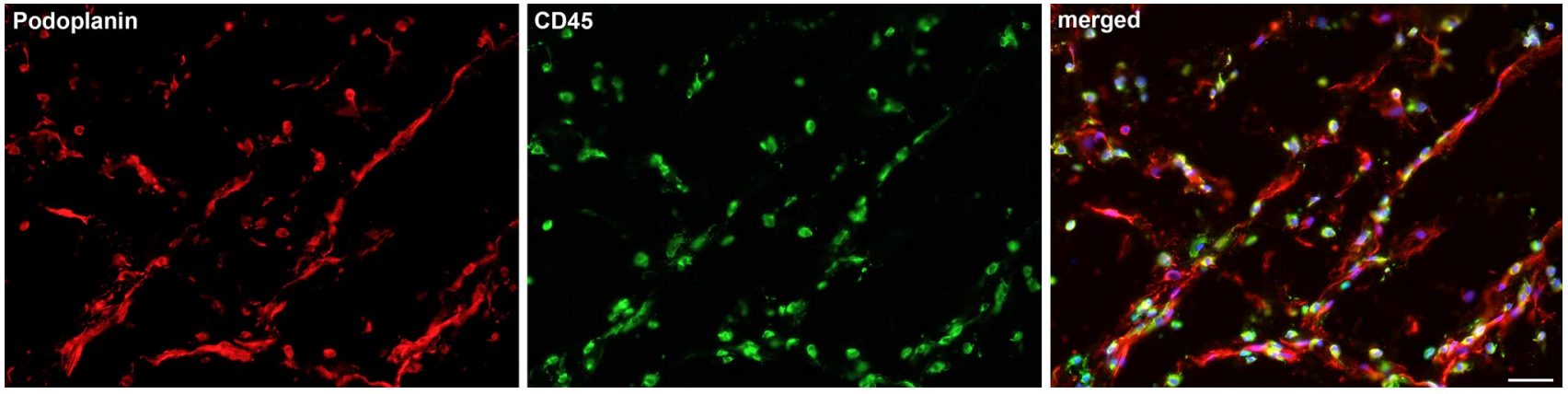

Fig. 2 Lymphatics in the Matrigel plugs are closely associated with leukocytes. Networks of lymphatic capillaries are demonstrated with the LEC marker podoplanin (red). Note that the distribution of leu-

speculate that autologous patient-derived EPCs may behave in a similar way and integrate into newly developing lymphatic networks, which might provide a therapeutic option for the treatment of lymphedema.

\section{Leukocytes in murine lymphangiogenesis}

Here, we studied lymphangiogenesis in adult mice and observed a striking co-localization of new lymphatics with $\mathrm{CD} 45^{+}$leukocytes. In an embryonic mouse model of lymphangiogenesis, a population of myeloid cells, characterized kocytes, stained with anti-CD45 antibodies (green), closely follows the pattern of the lymphatics. Nuclei are counter-stained with Dapi (blue). Bar $50 \mu \mathrm{m}$

by the expression of the tyrosine kinase Syk, was found to express the lymphangiogenic factors VEGF-C and -D, as well as various chemokines. The $\mathrm{Syk}^{+}$cell population comprises M2-polarized mononuclear cells and regulates developmental lymphangiogenesis (Böhmer et al. 2010). The effect of the $\mathrm{Syk}^{+}$cells could be inhibited in vivo by the application of soluble VEGFR-3, a specific inhibitor for VEGF-C and -D (Böhmer et al. 2010). An important function for VEGF$\mathrm{C}$-secreting macrophages and neutrophils has been reported in various murine lymphangiogenesis models (Schoppmann et al. 2002; Baluk et al. 2005; Gordon et al. 2010). 

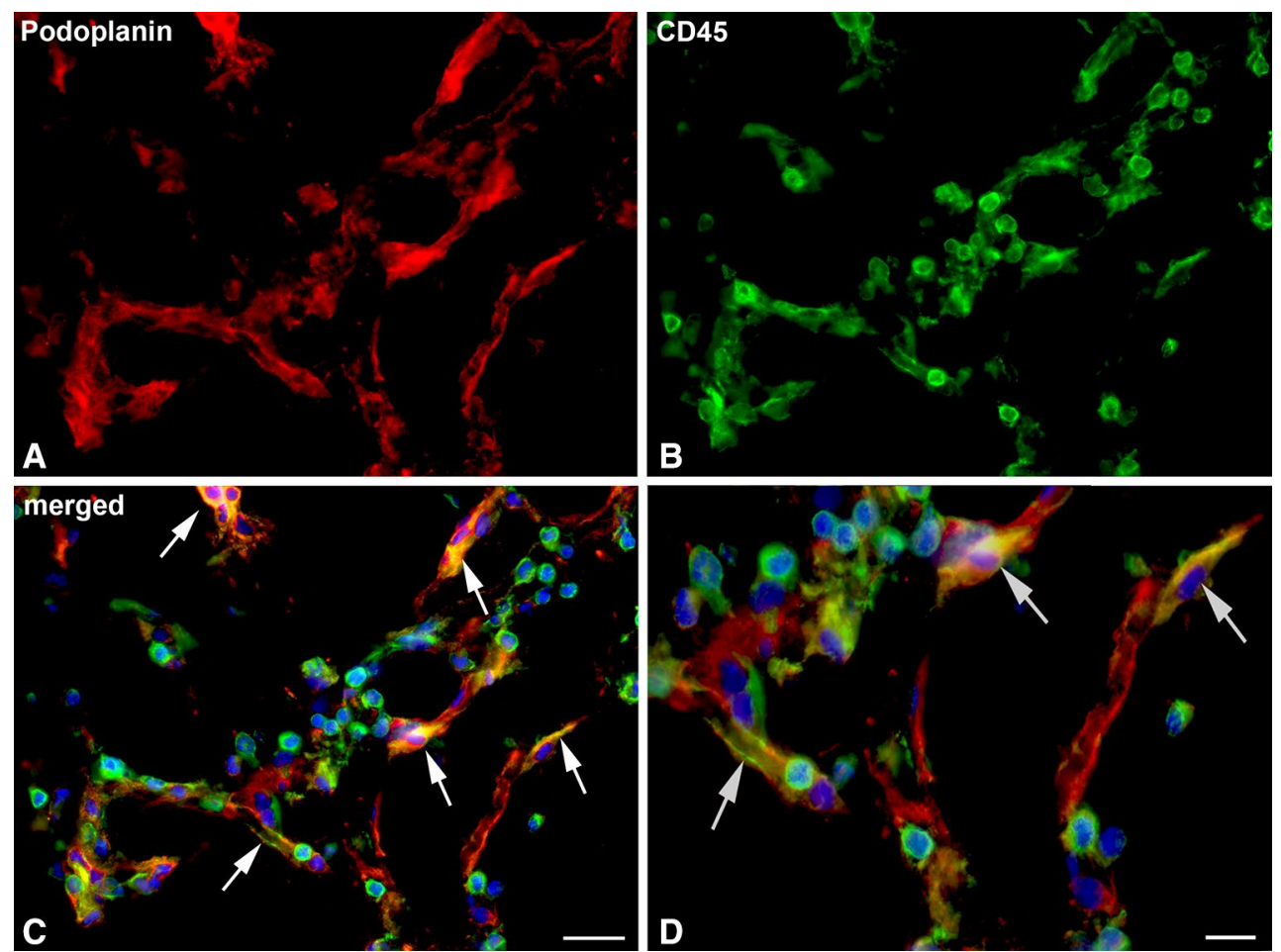

Fig. 3 A subpopulation of cells in the lymphatic networks are positive for both podoplanin and CD45. a Podoplanin (red). b CD45 (green). c Merged picture. Besides round CD45-positive cells, there are endothelial-like cells that co-express podoplanin and CD45 (arrows). Nuclei are counter-stained with Dapi (blue). Bar
$25 \mu \mathrm{m}$. (Modified from: Buttler et al. 2014; Springer license no.: 3699330937457). d Higher magnification of (c) note endothelial-like cells that co-express podoplanin and CD45 (arrows), indicating integration of leukocytes into developing lymphatic networks. Bar $10 \mu \mathrm{m}$
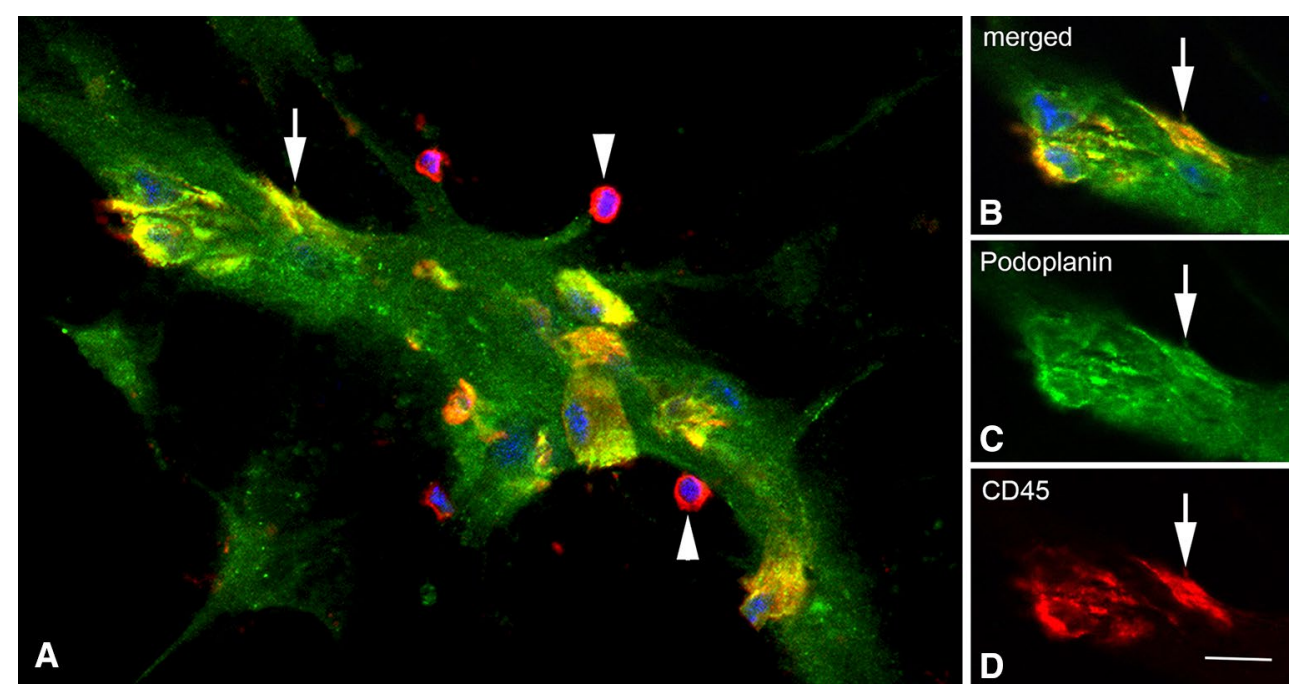

Fig. 4 Endothelial-like cells in the lymphatic sinusoids are positive for both podoplanin and CD45. a Merged picture of a podoplanin $^{+}$(green) lymphatic sinus. CD45 is shown in red. Besides round $\mathrm{CD}_{4} 5^{+}$leukocytes (arrowheads), there are endothelial-like cells (yellow) that co-express the two markers. b-d Merged picture and separate channels showing the cell marked with an arrow in (a). Bar $10 \mu \mathrm{m}$ 

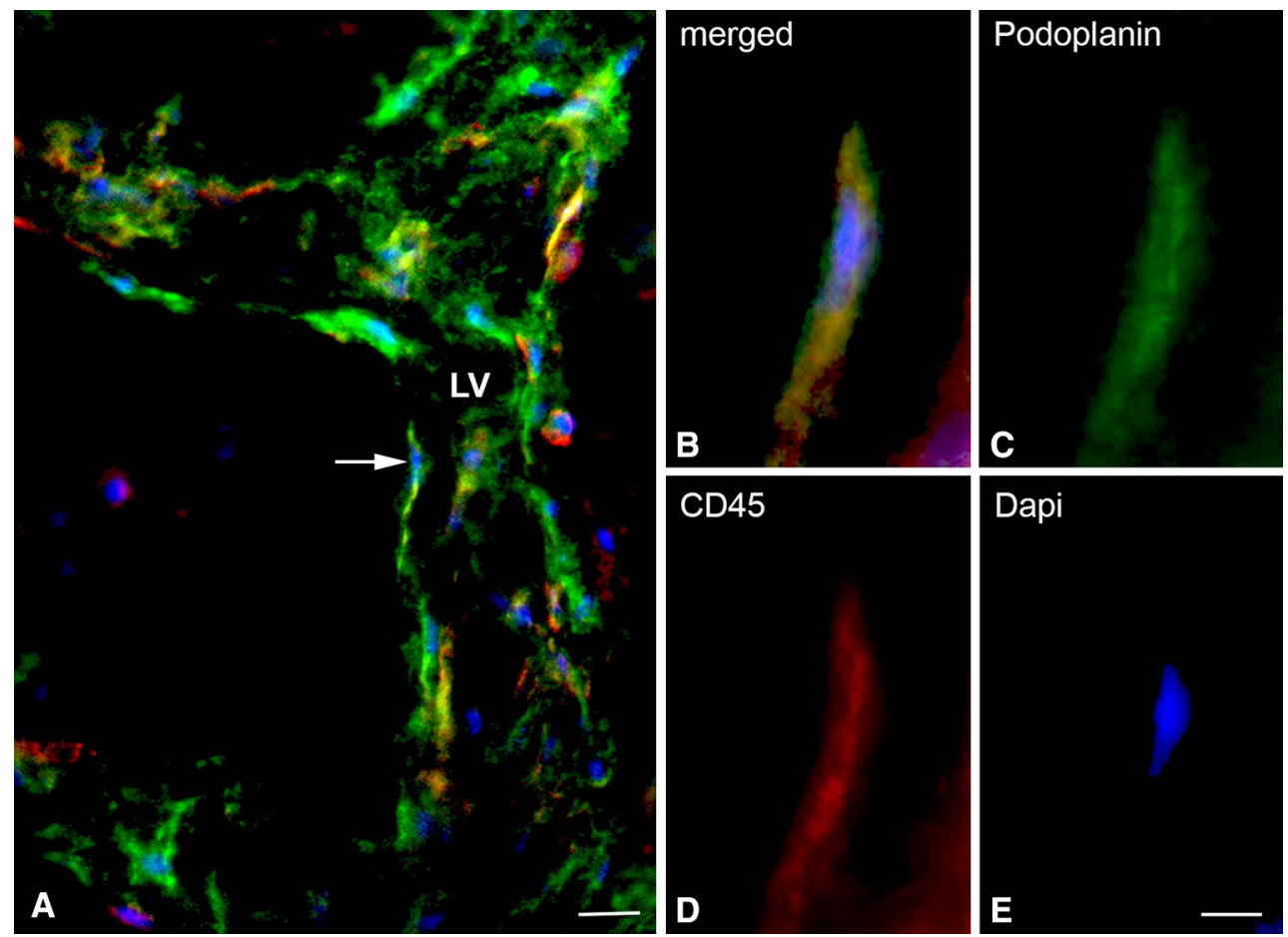

Fig. 5 Cells lining newly formed lymphatics express podoplanin and CD45. a Merged picture of a lymphatic vessel $(L V)$ in the Matrigel plug, stained for podoplanin (green) and CD45 (red). Nuclei are counter-stained with Dapi (blue). The vessels are lumenized and have

\section{Inflammation-induced lymphangiogenesis}

Our studies revealed an obvious co-localization of CD45 leukocytes with the newly forming lymphatic networks. The accumulation of leukocytes is known as a characteristic feature of inflammation. Consistent with this, EPCs and MSCs secrete chemoattractants such as CXCL1, 10 and 16, as well as MCP1 (Buttler et al. 2014). Among others, these factors attract macrophages, which can release angiogenic proteins such as VEGF-A and VEGF-C (Schoppmann et al. 2002; Mantovani et al. 2006). The contribution of macrophages to inflammation-induced lymphangiogenesis could, among others, be demonstrated in a macrophagedeficient mouse model (Kubota et al. 2009). Since we did neither observe any significant numbers of leukocytes in the Matrigel controls, nor in the experiments with EPCs, it is obvious that the attraction of leukocytes is induced by the grafted MSCs. As we have used a syngeneic C57/B1.6 mouse model, it is unlikely that leukocyte immigration is a sign for host-versus-graft reactions.

Human cornea and kidney transplant rejection shows most clearly that inflammation is a potent inducer of lymphangiogenesis. In the cornea, inflammation induces growth of lymphatics, which remain clinically invisible. Lymphangiogenesis then facilitates trafficking of two branches to the left. Bar $20 \mu \mathrm{m}$. b-e Merged picture and separate channels showing the cell marked with an arrow in (a). The cell lining the vessels expresses both podoplanin and CD45. Bar $8 \mu \mathrm{m}$

antigen-presenting cells from the cornea to draining lymph nodes, induction of hypersensitivity and corneal rejection (Chen et al. 2007). Similarly, in renal transplant rejection, inflammation is associated with a 50-fold increase in lymphatic vessel density and invasion of lymphatics into the tubulointerstitial stroma (Kerjaschki et al. 2004). Thereby, host cells, which obviously represent circulating lymphendothelial progenitor cells, integrate into the endothelial lining and contribute to the newly developing lymphatic networks (Kerjaschki et al. 2006). In this respect, the mouse model presented in our study deeply reflects the mechanisms of human inflammation-induced lymphangiogenesis.

\section{Embryonic lymphangiogenesis}

Regarding the embryonic development of the lymphovascular system, it is generally accepted that lymph sacs, the first histologically detectable structures of the lymphatic system, are formed by outgrowth of pre-lymphatic clusters from the cardinal veins (Sabin 1909; Pollmann et al. 2014). In recent years, the lymph sacs were proposed to represent the sole origin of the whole lymphatic system of mice (Srinivasan et al. 2007). However, an opposing theory claiming the existence of mesenchymal precursor cells, so-called lymphangioblasts, as a second source for the lymphatic 
vasculature is getting more and more conceivable. In 1910, Huntington and McClure were the first to speculate on the existence of mesenchymal precursor cells for LECs (Huntington and McClure 1910). Further evidence was found by analyzing the expression patterns of the LEC marker Prox 1 in mesenchymal cells of Xenopus, chicken and mouse embryos, revealing scattered cells of lymphatic character supposed to represent lymphangioblasts (Schneider et al. 1999; Ny et al. 2005; Buttler et al. 2006). Evidence for lymphangioblasts in both the intra-embryonic and the extraembryonic mesoderm of avian embryos was provided with quail-chick-transplantation experiments. Mesodermal cells of 2- to 3-day-old quail embryos are able to integrate into the host's lymph sacs, lymph hearts and allantoic lymphatics when transplanted into corresponding regions of chick embryos (Papoutsi et al. 2001; Wilting et al. 2000, 2006; Valasek et al. 2007). As cells of the macrophage/monocyte lineage were found to contribute to lymphangiogenesis in inflammation, they were suggested to participate in the embryonic formation of the lymphatic system, too. Transdifferentiation of macrophages to LECs was suggested, but, although Lyve-1-positive macrophages were found capable of integrating into the wall of developing lymphatics, Prox 1 expression was not detected. Hereby, trans-differentiation could be excluded (Gordon et al. 2010).

In mammals, the formation of embryonic blood vessels in a bipartite way is generally accepted, meaning there is (1) de novo formation of vessels from angioblasts (vasculogenesis) and (2) growth of vessels from preexisting ones by sprouting, splitting and intercalation (angiogenesis; Risau 1997). The existence of lymphangioblasts in mammals has been negated by a number of researchers in the field. However, recently elegant studies on mice have shown that a significant part of the dermal lymphatic vasculature is formed independently of venous sprouts. Using lineage-tracing experiments they could depict a non-venous origin of LECs in the lumbar skin and along the dorsal midline. In a process referred to as lymphvasculogenesis, these cells were found to assemble into clusters, subsequently generating vessels (Martinez-Corral et al. 2015). In a second study the same group could show that parts of the mesenteric lymphatic vasculature are formed from progenitors of hemogenic endothelial origin, thus representing further evidence for the lymphatic system being of multiple origin (Stanczuk et al. 2015). The hemogenic endothelium is the intra-embryonic source of blood cells. Together, the data show that murine lymphatics are derived from venous and non-venous origin, and the development of blood cells and LECs is closely connected. As shown in our study, the mechanisms of adult lymphangiogenesis recapitulate to a great extent those of the embryo. Lymphvasculogenic and lymphangiogenic mechanisms exist side by side. Thereby, adult lymphangioblasts like their embryonic counterparts may also be derived from hemogenic precursor cells.

Acknowledgments We thank Mrs. B. Pawletta and Mrs. I. Hollatz for their expert technical assistance in progenitor cell culture, and Mr. B. Manshausen for his valuable assistance in the preparation of immunohistological specimens.

\section{Compliance with ethical standards}

Conflict of interest The authors declare no conflicts of interest.

Open Access This article is distributed under the terms of the Creative Commons Attribution 4.0 International License (http://creativecommons.org/licenses/by/4.0/), which permits unrestricted use, distribution, and reproduction in any medium, provided you give appropriate credit to the original author(s) and the source, provide a link to the Creative Commons license, and indicate if changes were made.

\section{References}

Baluk P, Tammela T, Ator E, Lyubynska N, Achen MG, Hicklin DJ, Jeltsch M, Petrova TV, Pytowski B, Stacker SA, Ylä-Herttuala S, Jackson DG, Alitalo K, McDonald DM (2005) Pathogenesis of persistent lymphatic vessel hyperplasia in chronic airway inflammation. J Clin Investig 115(2):247-257

Böhmer R, Neuhaus B, Bühren S, Zhang D, Stehling M, Böck B, Kiefer F (2010) Regulation of developmental lymphangiogenesis by Syk + leukocytes. Dev Cell 18(3):437-449

Bussmann J, Bos FL, Urasaki A, Kawakami K, Duckers HJ, SchulteMerker S (2010) Arteries provide essential guidance cues for lymphatic endothelial cells in the zebrafish trunk. Development 137(16):2653-2657

Buttler K, Kreysing A, Von Kaisenberg CS, Schweigerer L, Gale N, Papoutsi M, Wilting J (2006) Mesenchymal cells with leukocyte and lymphendothelial characteristics in murine embryos. Dev Dyn 235(6): 1554-1562

Buttler K, Badar M, Seiffart V, Laggies S, Gross G, Wilting J, Weich HA (2014) De novo hem- and lymphangiogenesis by endothelial progenitor and mesenchymal stem cells in immunocompetent mice. Cell Mol Life Sci 71:1513-1527

Cha H-S, Bae E-K, Koh J-H, Chai J-Y, Jeon CH, Ahn K-S, Kim J, Koh E-M (2007) Tumor necrosis factor-alpha induces vascular endothelial growth factor-C expression in rheumatoid synoviocytes. J Rheumatol 34(1):16-19

Cha YR, Fujita M, Butler M, Isogai S, Kochhan E, Siekmann AF, Weinstein BM (2012) Chemokine signaling directs trunk lymphatic network formation along the preexisting blood vasculature. Dev Cell 22(4):824-836

Chen L, Hamrah P, Cursiefen C, Zhang Q, Pytowski B, Streilein JW, Dana MR (2007) Vascular endothelial growth factor receptor-3 mediates induction of corneal alloimmunity. Ocul Immunol Inflam 15(3):275-278

Földi E, Földi M (2003) Lymphoststic diseases. In: Földi M, Földi E, Kubik S (eds) Textbook of lymphology for physicians and lymphedema therapists. Elsevier, Munich, pp 231-319

Gordon EJ, Rao S, Pollard JW, Nutt SL, Lang RA, Harvey NL (2010) Macrophages define dermal lymphatic vessel calibre during development by regulating lymphatic endothelial cell proliferation. Development 137(22):3899-3910

Hoffmann A, Pelled G, Turgeman G, Eberle P, Zilberman Y, Shinar H, Keinan-Adamsky K, Winkel A, Shahab S, Navon G, Gross G, 
Gazit D (2006) Neotendon formation induced by manipulation of the Smad8 signalling pathway in mesenchymal stem cells. J Clin Investig 116(4):940-952

Hogan BM, Herpers R, Witte M, Heloterä H, Alitalo K, Duckers HJ, Schulte-Merker S (2009) Vegfc/Flt4 signalling is suppressed by Dll4 in developing zebrafish intersegmental arteries. Development 136(23):4001-4009

Huntington GS, McClure CFW (1910) The anatomy and development of the jugular lymph sacs in the domestic cat (Felis domestica). Am J Anat 10(1):177-312

Isogai S, Hitomi J, Yaniv K, Weinstein B (2009) Zebrafish as a new animal model to study lymphangiogenesis. Anat Sci Int 84(3):102-111

Kampmeier OF (1912) The development of the thoracic duct in the pig. Am J Anat 13(4):401-475

Kerjaschki D, Regele HM, Moosberger I, Nagy-Bojarski K, Watschinger B, Soleiman A, Birner P, Krieger S, Hovorka A, Silberhumer G, Laakkonen P, Petrova T, Langer B, Raab I (2004) Lymphatic neoangiogenesis in human kidney transplants is associated with immunologically active lymphocytic infiltrates. J Am Soc Nephrol 15(3):603-612

Kerjaschki D, Huttary N, Raab I, Regele H, Bojarski-Nagy K, Bartel G, Krober SM, Greinix H, Rosenmaier A, Karlhofer F, Wick N, Mazal PR (2006) Lymphatic endothelial progenitor cells contribute to de novo lymphangiogenesis in human renal transplants. Nat Med 12(2):230-234

Koltowska K, Betterman KL, Harvey NL, Hogan BM (2013) Getting out and about: the emergence and morphogenesis of the vertebrate lymphatic vasculature. Development 140(9):1857-1870

Konerding M, Gibney B, Houdek J, Chamoto K, Ackermann M, Lee G, Lin M, Tsuda A, Mentzer S (2012) Spatial dependence of alveolar angiogenesis in post-pneumonectomy lung growth. Angiogenesis 15(1):23-32

Kubota Y, Takubo K, Shimizu T, Ohno H, Kishi K, Shibuya M, Saya H, Suda T (2009) M-CSF inhibition selectively targets pathological angiogenesis and lymphangiogenesis. J Exp Med 206(5):1089-1102

Küchler AM, Gjini E, Peterson-Maduro J, Cancilla B, Wolburg H, Schulte-Merker S (2006) Development of the zebrafish lymphatic system requires vegfc signaling. Curr Biol 16(12):1244-1248

Lin R-Z, Moreno-Luna R, Zhou B, Pu W, Melero-Martin J (2012) Equal modulation of endothelial cell function by four distinct tissue-specific mesenchymal stem cells. Angiogenesis 15(3):443-455

Mantovani A, Schioppa T, Porta C, Allavena P, Sica A (2006) Role of tumor-associated macrophages in tumor progression and invasion. Cancer Metastasis Rev 25(3):315-322

Martinez-Corral I, Ulvmar M, Stanczuk L, Tatin F, Kizhatil K, John SW, Alitalo K, Ortega S, Makinen T (2015) Non-venous origin of dermal lymphatic vasculature. Circ Res 116:1649-1654

Melero-Martin JM, De Obaldia ME, Kang S-Y, Khan ZA, Yuan L, Oettgen P, Bischoff J (2008) Engineering robust and functional vascular networks in vivo with human adult and cord bloodderived progenitor cells. Circ Res 103(2):194-202

Ny A, Koch M, Schneider M, Neven E, Tong RT, Maity S, Fischer C, Plaisance S, Lambrechts D, Héligon C, Terclavers S, Ciesiolka M, Kälin R, Man WY, Senn I, Wyns S, Lupu F, Brändli A, Vleminckx K, Collen Dewerchin M, Conway EM, Moons L, Jain RK, Carmeliet P (2005) A genetic Xenopus laevis tadpole model to study lymphangiogenesis. Nat Med 11(9):998-1004

Papoutsi M, Tomarev SI, Eichmann A, Pröls F, Christ B, Wilting J (2001) Endogenous origin of the lymphatics in the avian chorioallantoic membrane. Dev Dyn 222(2):238-251
Pollmann C, Hägerling R, Kiefer F (2014) Visualization of lymphatic vessel development, growth, and function. In: Kiefer F, SchulteMerker S (eds) Developmental aspects of the lymphatic vascular system SE-13. Springer, Vienna, pp 167-186

Pullinger BD, Florey HW (1937) Proliferation of lymphatics in inflammation. J Pathol Bacteriol 45(1):157-170

Risau W (1997) Mechanisms of angiogenesis. Nature 386(6626):671-674

Sabin FR (1909) The lymphatic system in human embryos, with a consideration of the morphology of the system as a whole. Am J Anat 9(1):43-91

Schneider M, Othman-Hassan K, Christ B, Wilting J (1999) Lymphangioblasts in the avian wing bud. Dev Dyn 216(4-5):311-319

Schniedermann J, Rennecke M, Buttler K, Richter G, Stadtler AM, Norgall S, Badar M, Barleon B, May T, Wilting J, Weich HA (2010) Mouse lung contains endothelial progenitors with high capacity to form blood and lymphatic vessels. BMC Cell Biol 11:50

Schoppmann SF, Birner P, Kalt R, Ullrich R, Caucig C, Kriehuber E, Nagy K, Alitalo K, Kerjaschki D, Stöckl J (2002) Tumor-associated macrophages express lymphatic endothelial growth factors and are related to peritumoral lymphangiogenesis. Am J Pathol 161(3):947-956

Schulte-Merker S, Sabine A, Petrova TV (2011) Lymphatic vascular morphogenesis in development, physiology, and disease. J Cell Biol 193(4):607-618

Soleimani M, Nadri S (2009) A protocol for isolation and culture of mesenchymal stem cells from mouse bone marrow. Nat Protoc 4(1):102-106

Srinivasan RS, Dillard ME, Lagutin OV, Lin F-J, Tsai S, Tsai M-J, Samokhvalov IM, Oliver G (2007) Lineage tracing demonstrates the venous origin of the mammalian lymphatic vasculature. Genes Dev 21(19):2422-2432

Stanczuk L, Martinez-Corral I, Ulvmar MH, Zhang Y, Laviña B, Fruttiger M, Adams RH, Saur D, Betsholtz C, Ortega S, Alitalo K, Graupera MT (2015) cKit lineage hemogenic endotheliumderived cells contribute to mesenteric lymphatic vessels article cKit lineage hemogenic endothelium-derived cells contribute to mesenteric lymphatic vessels. Cell Rep 10:1708-1721

Tammela T, Alitalo K (2010) Lymphangiogenesis: molecular mechanisms and future promise. Cell 140(4):460-476

Valasek P, Macharia R, Neuhuber WL, Wilting J, Becker DL, Patel K (2007) Lymph heart in chick-somitic origin, development and embryonic oedema. Development 134(24):4427-4436

Wilting J, Papoutsi M, Schneider M, Christ B (2000) The lymphatic endothelium of the avian wing is of somitic origin. Dev Dyn 217(3):271-278

Wilting J, Papoutsi M, Christ B, Nicolaides KH, von Kaisenberg CS, Borges J, Stark GB, Alitalo K, Tomarev SI, Niemeyer C, Rössler $\mathrm{J}$ (2002) The transcription factor Prox 1 is a marker for lymphatic endothelial cells in normal and diseased human tissues. FASEB J 16(10):1271-1273

Wilting J, Aref Y, Huang R, Tomarev SI, Schweigerer L, Christ B, Valasek P, Papoutsi M (2006) Dual origin of avian lymphatics. Dev Biol 292(1):165-173

Wilting J, Becker J, Buttler K, Weich HA (2009) Lymphatics and inflammation. Curr Med Chem 16(34):4581-4592

Yaniv K, Isogai S, Castranova D, Dye L, Hitomi J, Weinstein BM (2006) Live imaging of lymphatic development in the zebrafish. Nat Med 12(6):711-716 